\title{
Psychological Aspects of Treatment with Intragastric Balloon for Management of Obesity: A Systematic Review of the Literature
}

\author{
Giada Pietrabissa ${ }^{a, b}$ Vanessa Bertuzzi ${ }^{a}$ Susan Simpson ${ }^{c, d}$ \\ Anna Guerrini Usubini ${ }^{a}$ b Roberto Cattivellia, ${ }^{b}$ Simona Bertoli ${ }^{e, f}$ \\ Enrico Mozzi ${ }^{9}$ Giancarlo Roviaro ${ }^{9}$ Gianluca Castelnuovo a,b Enrico Molinaria b \\ aDepartment of Psychology, Catholic University of Milan, Milan, Italy; 'bstituto Auxologico Italiano IRCCS, \\ Psychology Research Laboratory, Milan, Italy; ${ }^{C}$ Department of Justice and Society, University of South Australia,

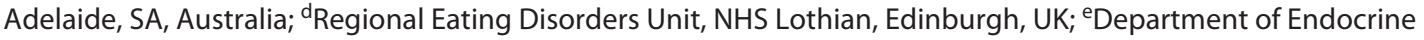 \\ and Metabolic Diseases, Obesity Unit and Laboratory of Nutrition and Obesity Research, Istituto Auxologico Italiano \\ IRCCS, Milan, Italy; ${ }^{f}$ Department of Food, Environmental and Nutritional Sciences, International Center for the \\ Assessment of Nutritional Status, University of Milan, Milan, Italy; ${ }^{9}$ Division of General Surgery, Istituto Auxologico \\ Italiano IRCCS, Milan, Italy
}

\section{Keywords}

Intragastric balloon · Obesity · Mood disorders · Quality of life $\cdot$ Clinical psychology

\footnotetext{
Abstract

Introduction: Optimizing maintenance of weight loss for people with obesity following intragastric balloon (IGB) therapy hinges on the degree to which health care providers can recognize both the impact of emotional problems and mood difficulties on their capacity to self-manage, and requirements for additional support. However, there is limited research on the psychological correlates of IGB therapy. This systematic review, for the first time, attempts to identify and synthesize the empirical evidence for the reciprocal influence between psychological variables and IGB outcomes. Methods: A literature search was performed in the PubMed, SCOPUS, MEDLINE, and Google Scholar databases. Preferred Reporting Items for Systematic Reviews and Meta-Analyses
}

karger@karger.com www.karger.com/ofa

Karger $\stackrel{\text { ' }}{5}$

BOPEN ACCESS
(C) 2021 The Author(s)

Published by S. Karger AG, Basel

This is an Open Access article licensed under the Creative Commons Attribution-NonCommercial-4.0 International License (CC BY-NC) (http://www.karger.com/Services/OpenAccessLicense), applicable to the online version of the article only. Usage and distribution for commercial purposes requires written permission. guidelines were followed using rigorous inclusion criteria and screening by at least 2 reviewers. The selected articles were assessed for quality using the Strengthening the Reporting of Observational Studies Epidemiology (STROBE) checklist. Data were extracted to address the review aims and presented as a narrative synthesis. The review protocol was preregistered (Prospero CRD42019121291). Results: A total of 16,179 titles, 14,369 abstracts, and 51 full-text articles were screened, of which 16 studies were included. Findings suggest that female gender, older age, basic educational lev$\mathrm{el}$, and single/divorced civil status, together with lower levels of depression, binge eating, higher perceived quality of life, and motivation to change were predictors of enhanced IGB treatment outcomes. Dissatisfaction with treatment was higher in those with impaired obesity-related social-life difficulties. The IGB treatment was effective in reducing weight and improving depression, anxiety, eating disorder symptoms, and the overall life quality of patients with obesity mainly within 6 months from the device positioning and in 
conjunction with conventional therapies. Discussion/Conclusion: In line with the available literature on obesity and bariatric surgery interventions, poor mental health appears to be an important barrier for successful weight loss among patients with obesity undergoing IGB treatment. In order to improve the efficacy and effectiveness of the IGB therapy, more comprehensive and standardized studies are needed to provide insight into the psychological mechanisms maintaining weight management issues.

(C) 2021 The Author(s).

Published by S. Karger AG, Basel

\section{Introduction}

Obesity is a major health problem that independently contributes to the development and progression of chronic diseases, with prevalence rates that are likely to increase significantly in the near future $[1,2]$. With the failure of conventional treatments for weight loss - including pharmacological (e.g., appetite suppressants) and lifestyle modification programs - bariatric surgery is recognized as the most effective long-term solution for severe and complex obesity [3]. However, bariatric procedures are limited to candidates with a body mass index $(\mathrm{BMI}) \geq 40$ or $35-40 \mathrm{~kg} / \mathrm{m}^{2}$ with obesity-related comorbidities [4]. Following bariatric surgery, candidates may also experience procedure-specific problems with enduring consequences - such as nutritional deficiencies, problematic eating behaviors and dumping syndrome requiring long-term follow-up care that is too often flouted [5].

Intragastric balloons (IGB) offer a potentially safer and temporary (up to 6 months) endoscopic nonsurgical treatment option for those patients with obesity who repeatedly fail to lose weight through traditional methods such as dieting or exercise, and refuse or are unsuitable for weight loss surgery [6]. It can also be used prior to weight loss surgery to reduce obesity-related comorbidities and to facilitate the implementation of new dietary and behavioral habits. This procedure involves placing a spherical balloon of silicone, filled with saline or air, into the stomach in order to reduce gastric capacity and to provide a continuous sensation of satiety, which will result in decreasing food intake and facilitating maintenance of a low-calorie diet [7]. The IGB has been shown effective in reducing weight loss and allowing weight loss maintenance up to 5 years after removal in a sample of 500 individuals with obesity [8]. It has been also shown effective in treating a sample of 261 overweight patients from Italy, Belgium, and Spain up to 3 years after removal [9]. Moreover, a recent study revealed that the percentage of patients with obesity unresponsive to IGB treatment is similar to that of those undergoing bariatric surgery [10]. It, therefore, represents an effective noninvasive practice for preliminary testing of adherence to treatment recommendations in bariatric surgery candidates.

However, responses to IGB treatment are highly variable between individuals [11], and successful weight loss largely depends on multiple factors including genetic, cultural, environmental, behavioral, and psychological determinants [12-16]. Indeed, people with obesity seeking treatment - no matter whether surgical or nonsurgical - commonly register high rates of psychopathologies, such as anxiety and depressive symptoms $[17,18]$, eating problems, internalized weight bias, and body shame [19-22], together with lower levels of selfesteem and perceived quality of life (QoL) [23-25], which significantly affect the individuals' ability to selfmanage and the maintenance of long-term weight loss outcomes [26]. Further, research shows that patients with 2 or more psychiatric diagnoses are significantly more likely to experience weight loss cessation or weight regain after 1 year than those with $<2$ psychiatric diagnoses $[27,28]$.

To identify the impact of mood disorders on the individuals' capability to adhere to treatment recommendations, the recognition of possible emotional impairments or needs is, therefore, essential to support the person throughout the treatment course and to improve weight loss outcomes after IGB treatment. Nevertheless, while the medical benefits' bariatric surgery and IGB therapy have been well established [29-31], the extent to which surgery procedures alleviate psychological difficulties in individuals with obesity remains unanswered [32-35], and the psychological factors associated with successful IGB treatment have been less studied and are therefore less understood [36].

Furthermore, as a systematic review in this area has not yet been conducted, the current work provides a valuable starting point to inform and assist mental health providers in the pre-post evaluation and monitoring of the psychological health of people with obesity undergoing IGB treatment. Therefore, the primary aim of this study is to systematically review the research literature in order to provide a comprehensive summary of the impact of psychiatric symptoms on IGB treatment outcomes, and to identify whether weight fluctuations following IGB treatment help to improve individuals' psychological functioning over time. 
Fig. 1. PRISMA flow diagram. PRISMA, Preferred Reporting Items for Systematic reviews and Meta-Analyses.

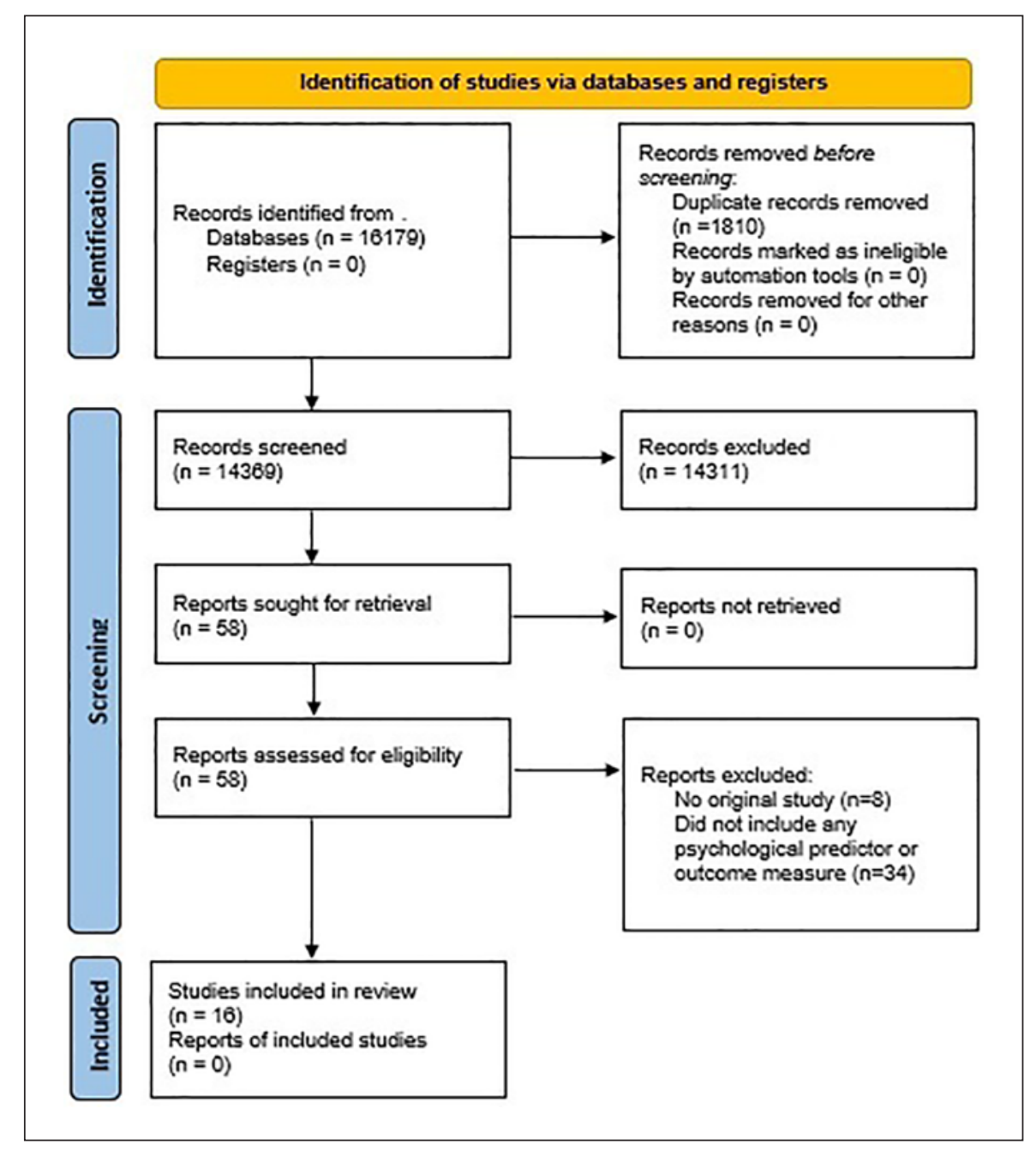

\section{Methods}

This review adhered to the Preferred Reporting Items for Systematic reviews and Meta-Analyses (PRISMA) guidelines [37] (see online suppl. Table 1; for all online suppl. material, see www. karger.com/doi/10.1159/000518200) and was registered with the PROSPERO international prospective register of systematic reviews (CRD42019121291).

\section{Search Strategy}

A literature search was conducted using PubMed, Scopus MEDLINE, and Google Scholar databases. Searches were carried out between January 14 and January 21, 2021. In accordance with the PICO framework (Patient Problem or Population; Intervention; Comparison or Control, and Outcome) [38], the search strategies combined key terms and Medical Search Headings (MESH) terms for the concepts of obesity, intragastric balloon, psychological construct of depression, anxiety, and binge eating, health-related quality of life (HRQoL) [39]. Boolean and truncation operators were used to more systematically combine search terms and to list documents containing variations on search terms, respectively [40]. The search syntax was modified as appropriate for each database.

\section{Inclusion and Exclusion Criteria}

Only original articles that (1) employed a quantitative research methodology, (2) included at least 1 psychological predictor or outcome measure of the IGB intervention, and (3) used an HRQoL instrument comprising at least 1 dimension of mental health were retained. Studies were excluded if (1) included animals or (2) considered only biomedical predictors or outcomes. No limitations were set for study design, language, ethnicity, and year of publication.

\section{Study Selection}

Following the search and exclusion of duplicates, 2 reviewers (authors V.B. and A.G.U.) independently screened the eligibility of the articles first on the title and the abstract, and on the full-text according to the inclusion criteria. Disagreements were resolved by reviewer G.P. The reference lists of all selected articles and relevant systematic reviews $[41,42]$ that were manually screened to identify any further references for possible inclusion. In accor- 
dance with Smith et al. [43], the review team included at least 1 person with methodological expertise in conducting systematic reviews (G.P. and V.B.) and at least 2 experts on the topic under review (G.P., S.B., and G.C.). Searches of electronic databases identified 16,179 reports, of which 1,810 were duplicate and 14,311 studies were excluded based on information from the title and the abstract. The remaining 58 articles were evaluated for inclusion by reviewing their full-text and resulted in the exclusion of 42 records for the following reasons [1]: they were not the original study - but systematic reviews of the literature $(n=8)$ [2] and did not include any psychological predictor or outcome measure $(n=34)$. References for the 16 remaining articles [44-59] and retrieved systematic review/meta-analysis [14, 36, 41, 42, 60-63] were further screened for relevant records, but none was found. In accordance with the PRISMA guidelines [64], the flowchart presented in Figure 1 provides step by step details of the study selection process.

\section{Assessment of Risk of Bias}

The Strengthening the Reporting of Observational Studies in Epidemiology (STROBE) checklist [65] was used to provide a description of the included studies following 11 domains: (1) article's title and abstract; (2-3) introduction; (4-12) methods; (13-17) results; (18-21) discussion; and (22) further information. Assessment was conducted independently by authors V.B. and A.G.U., and any disagreements resolved by a third author (G.P.).

Data Extraction and Synthesis

Authors G.P. and V.B. independently extracted the following data from included studies: (1) first author and year of publication, (2) country, (3) study aim, (4) study design, (5) follow-up points, (6) sample size, (7) age, (8) gender, (9) BMI, (10) body weight (BW), (11) psychological predictors and outcomes (and related measures), (12) biomedical outcomes, and (13) results (biomedical and psychological variables).

The 2 reviewers discussed any discrepancies, and, if necessary, consulted a third team member (author G.P.) to reach a final decision (Table 1). Extracted data were collated to produce a narrative summary of the psychological predictors and outcomes of IGB therapy to address the review questions.

\section{Results}

\section{Description of the Included Studies: The STROBE Checklist}

With 23 out of 34 methodological criteria properly met, the more rigorous studies were Tayyem et al. [56] and Kotzampassi et al. [50], while Tottè et al.'s study [51] was the weakest. The most frequently reported STROBE checklist items were as follows: providing an informative abstract of the study procedure and findings (ITEM \#1b); explaining the scientific background and rationale for the investigation being reported (ITEM \#2); stating of specific objectives, including any prespecified hypotheses (ITEM \#3); and key elements of study design (ITEM \#4) early in the study; giving eligibility criteria, sources, and methods of selection of participants (ITEM \#6a); clearly defining all outcomes (ITEM \#7); providing sources of data (ITEM \#8); explaining how the study size was arrived at (ITEM \#10) and how quantitative variables were handled in the analyses (ITEM \#11), describing all statistical methods, including those used to control for confounding (ITEM \# 12a); reporting the numbers of individuals at each stage of the study (ITEM \#13a); giving characteristics of study participants and information on exposures and potential confounders (ITEM \# 14a); reporting of the numbers of outcome events or summary measures (ITEM \#15); making clear which confounders were adjusted for and why they were included (ITEM \#16a); summarizing key results with reference to study objectives (ITEM \#18); and providing a cautious interpretation of results considering the objectives and explaining the results of similar studies (ITEM \#20). Specifically, all the selected contributions provided an informative abstract (ITEM \#1b), reported numbers of outcome events or summary measures (ITEM \#15), gave unadjusted estimates (ITEM \#16a), summarized key results with reference to the study objectives (ITEM \#18), and provided a careful interpretation of results (ITEM \#20). Conversely, unreported STROBE checklist items across studies were: description of any efforts to address potential sources of bias (ITEM \#9); matching criteria and number of exposed and unexposed (ITEM \#6b); explanation of how missing data were addressed (ITEM \#12c); reporting of any sensitivity analyses (ITEM \#12e) and summary of follow-up time (ITEM \#14c); and translating estimates of relative risk into absolute risk for a meaningful time period (ITEM \#16c).

The descriptive nature of the STROBE checklist does not enable a quantitative evaluation of the quality of the selected records - therefore no record was excluded from the present systematic review. Still, since this tool provides valuable recommendations for authors when conducting and reporting the results of observational studies, supports editors and reviewers when considering contributions for publication, and helps readers to critically appraise scientific reporting [65], its use was intended to improve the interpretation, discussion, and generalization of studies' findings. The STROBE statements are described in the online suppl. Table 2.

\section{Characteristics of the Included Studies}

Selected studies were published between 2001 [51] and 2018 [53, 54]. Seven out of 16 investigations used a prospective comparative design [48-50, 55-57, 59], while the remaining 9 records employed a prospective single-group observational design type. 


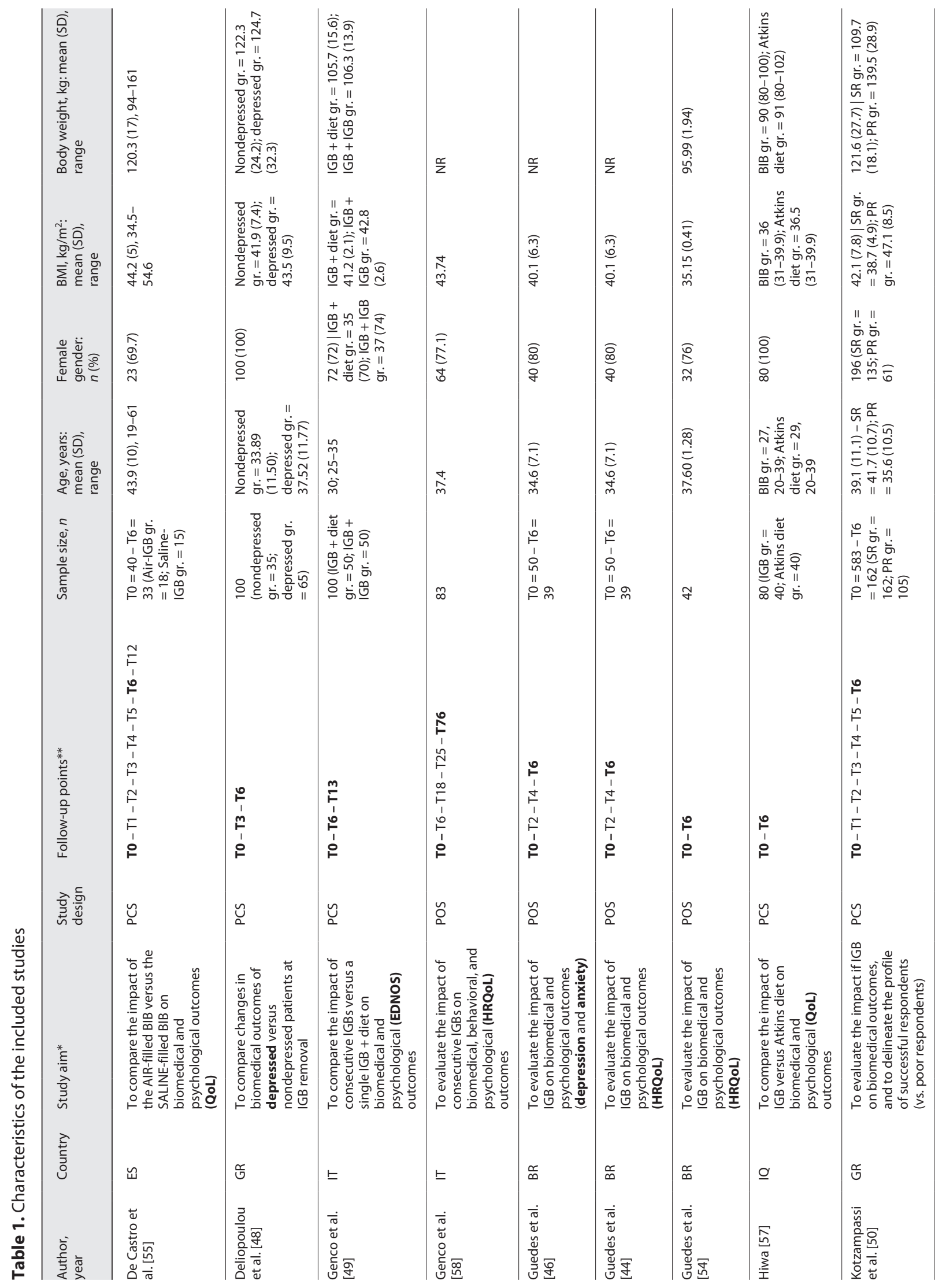




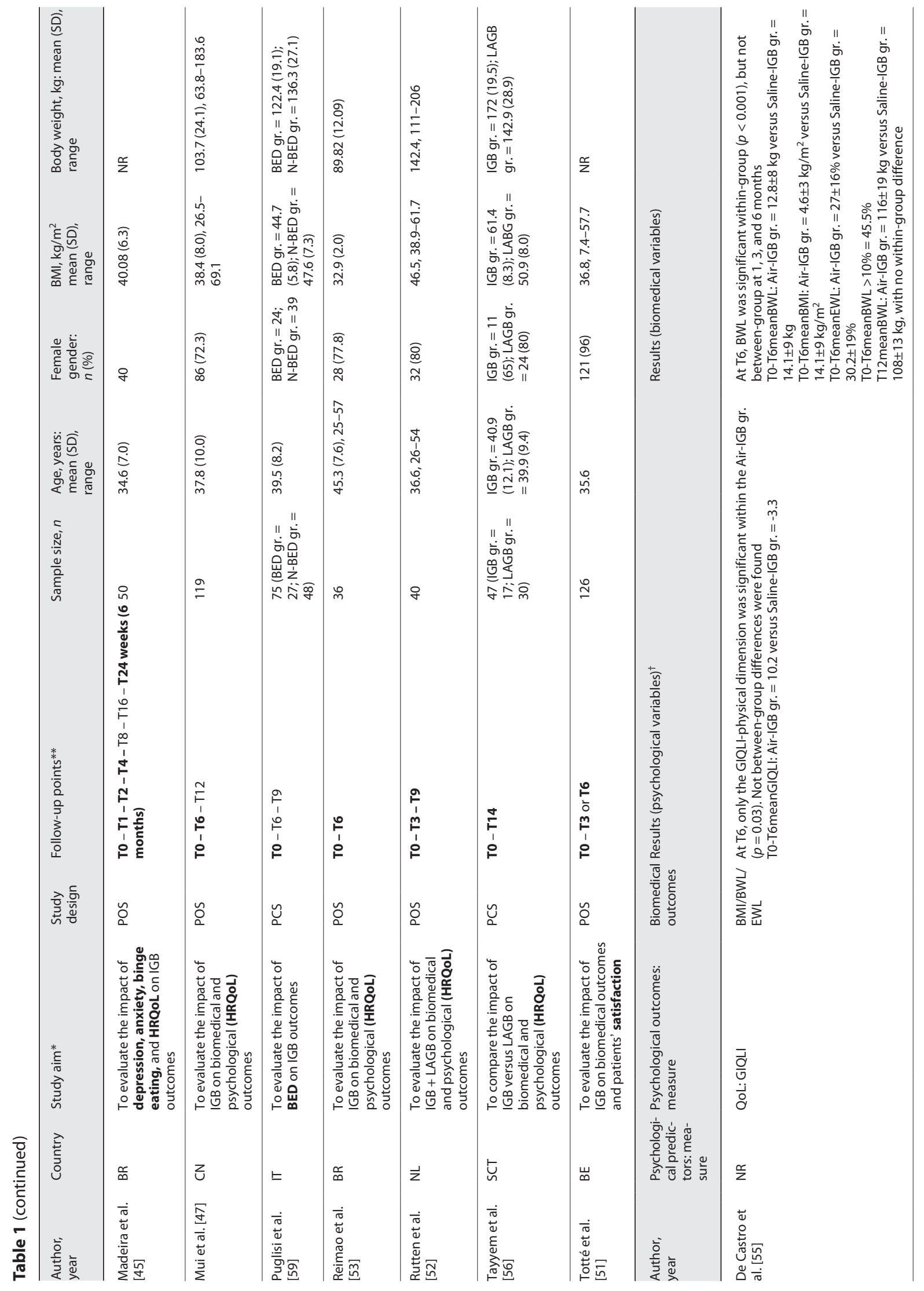



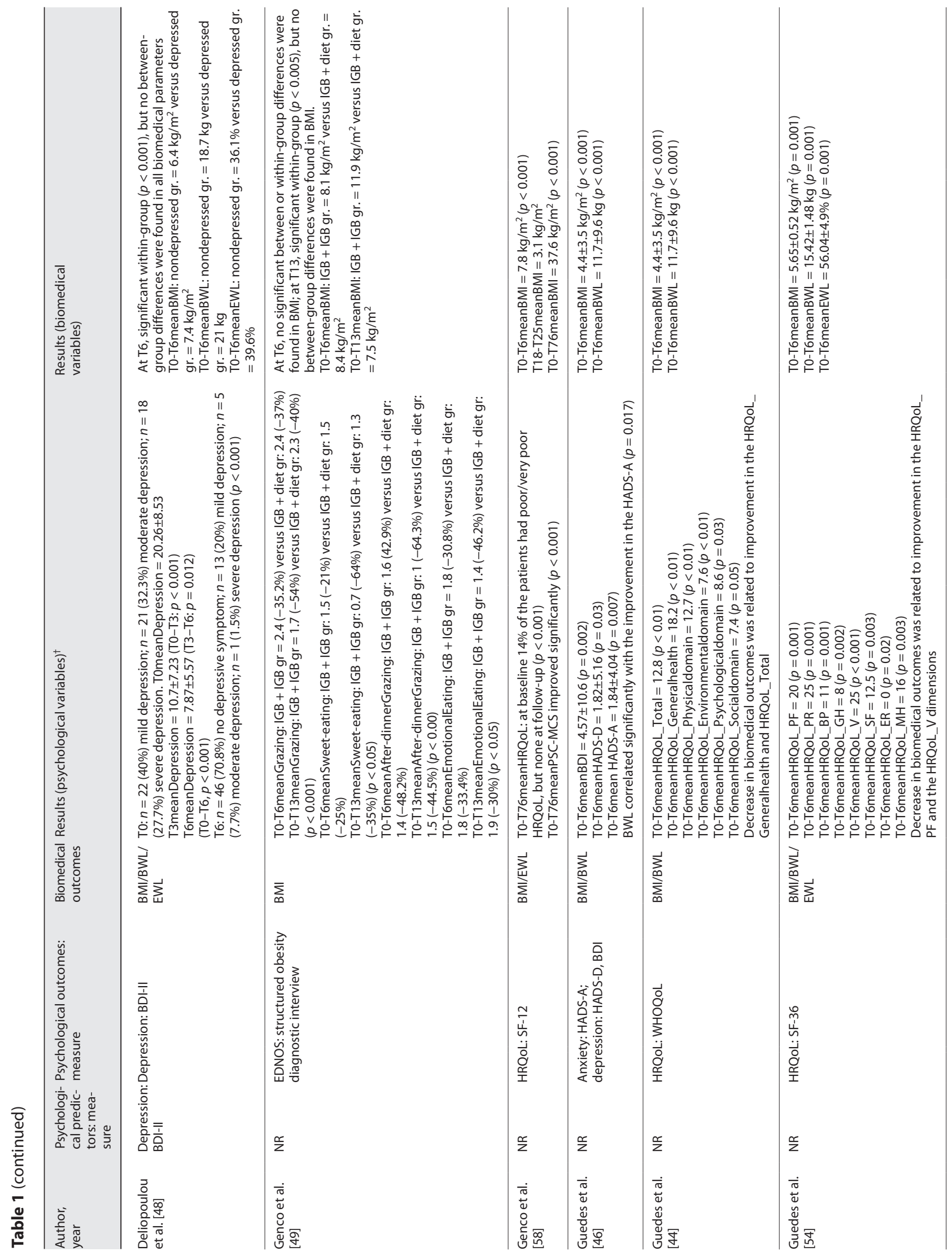


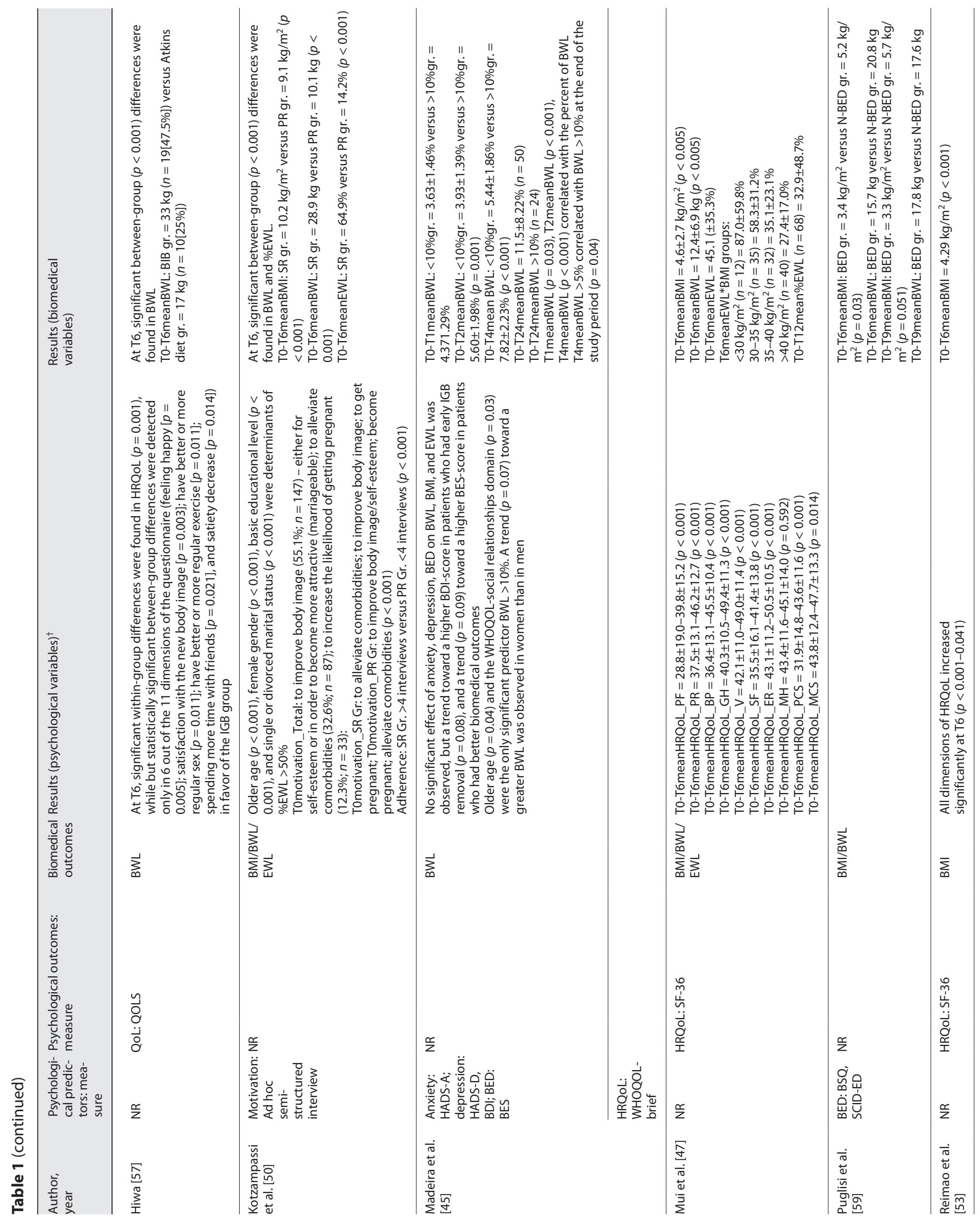




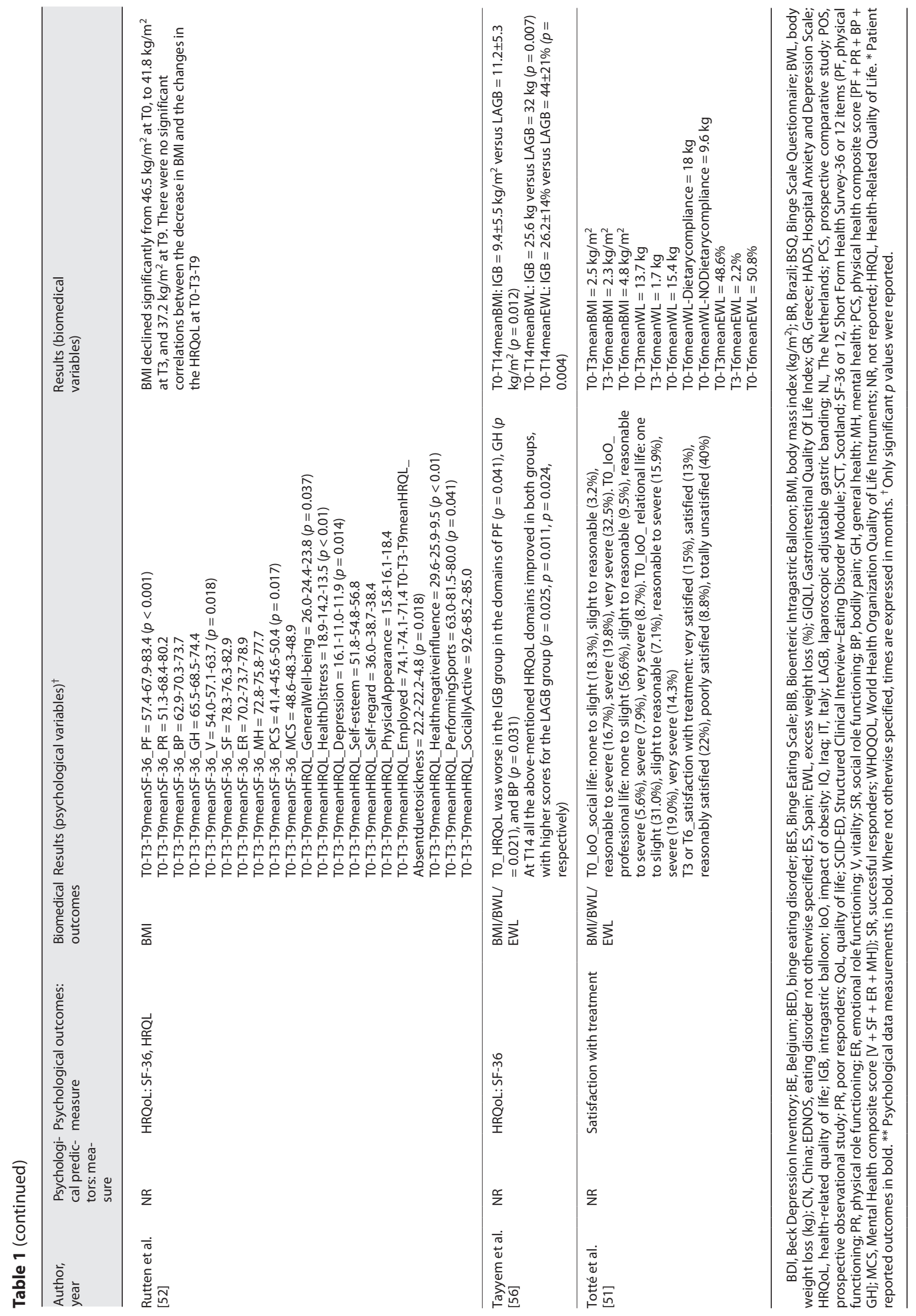


Most of the investigations were conducted in Brazil $(n=5)[44-46,53,54], 3$ studies in Italy $[49,58,59]$, and 2 in Greece $[48,50]$, while the remaining research was carried out in China $(n=1)$ [47], Scotland $(n=1)$ [56], Belgium $(n=1)$ [51], the Netherlands $(n=1)$ [52], Iraq $(n=1)$ [57], and Spain $(n=1)$ [55]. The sample size varied widely among studies, from a minimum of 36 persons [52] to a maximum of 583 individuals with an IGB [50]. Except for Deliopoulou et al. [48] and Hiwa [57] - which only enrolled females - the other studies included participants of both genders. The individuals' mean age ranged from 20 [57] to 60 years [55]. The population included in the study by Tayyem et al. [56] reported the highest BW $(89.82 \pm 12.09 \mathrm{~kg})$ and BMI $(32.9 \pm 2.0 \mathrm{~kg} /$ $\mathrm{m}^{2}$ ) levels at baseline, while the lowest baseline BW (172 $\pm 19.50 \mathrm{~kg})$ and $\mathrm{BMI}\left(61.4 \pm 8.3 \mathrm{~kg} / \mathrm{m}^{2}\right)$ values were found in Reimao et al. [53].

Three studies $[45,50,59]$ aimed at assessing the predicting role of anxiety [45] and depression [45], binge eating disorder (BED) [45, 59], HRQoL [45], and motivation to change [50] on IGB outcomes, while 12 articles [44, 46, $47,49,51-58]$ investigated the impact of the IGB treatment on psychological indices including anxiety [44] and depression [44], HRQoL [44, 47, 52-54, 56, 58], and QoL $[55,57]$. Satisfaction with treatment was also explored in 1 record [51]. Only 1 study considered psychological variables (depression) as both predictors and outcomes of the IGB intervention [48]. Psychological outcomes were measured from a minimum of 3 months after the IGB positioning $[48,51,52]$ to a maximum follow-up period of 76 months [58]. Details of the included studies are shown in Table 1.

Psychological Predictors of IGB Treatment

Outcomes

Anxiety and Depression

Madeira et al. (2016) instigated the predictive role of anxiety and depression (by means of the Hospital Anxiety and Depression Scale, HADS) on weight loss among 50 patients with IGB at device removal (after 6 months). They found no significant effect of mood disorders on BW, BMI, and excess weight loss (\%EWL), but a trend $(p=0.08)$ toward a higher score in the Beck Depression Inventory (BDI) was observed in patients who experienced early IGB removal [45]. In contrast, by comparing a sample of nondepressed women $(n=35)$ with a population of mildly, moderately, and severely depressed females with obesity $(n=65)$, Deliopoulou et al. [48] registered a highly statistically significant difference in BW loss (nondepressed:18.7 kg vs. depressed $=21 \mathrm{~kg}$ ), BMI (nondepressed $=6.4 \mathrm{~kg} / \mathrm{m}^{2}$ vs. depressed $=7.4 \mathrm{~kg} / \mathrm{m}^{2}$ ), and $\% \mathrm{EWL}$ (nondepressed $=36.1 \%$ vs. depressed $=$ $39.6 \%)$ at IGB removal in both groups $(p<0.001)$, with more favorable outcomes among those less severely depressed at baseline.

\section{Binge Eating Disorder}

In the study by Madeira et al. [45], binge eating did not account for IGB-related BW loss ( $>10 \%)$ at device removal, but a trend $(p=0.09)$ toward higher scores on the Binge Eating Scale was observed in patients who achieved better outcomes. In contrast, Puglisi et al. (2007) investigated the influence of BED symptoms (measured by the Eating Disorder Module of the Structured Clinical Interview, ED-SCID, and the Binge Scale Questionnaire, BSQ) on the decrease in BW and BMI of 75 patients with obesity undergoing IGB treatment (BED gr. $=27$ vs. No-BED gr. $=48$ ). Both the participants with BED and those who did not show baseline binge eating symptoms achieved a statically significant reduction in BW and BMI at treatment termination $(p<0.01)$, but BMI decreased less in the BED group than in their non-binge eating counterparts (BED gr. $=3.3 \mathrm{~kg} / \mathrm{m}^{2}$ vs. No-BED gr. $=5.7 \mathrm{~kg} / \mathrm{m}^{2}$; $p=0.03)$ [59].

\section{Health-Related Quality of Life}

Together with anxiety, depression, and binge eating, Madeira et al. (2016) also considered the perceived HRQoL of the sample as a predictor of the IGB treatment outcomes. Only the social relationship domain of the WHOQOL brief ( $p=0.02$ ) was found to predict successful BW decrease at device removal. Older age $(p=0.04)$ also significantly correlated with $\mathrm{BW}$ loss $>10 \%$, and a positive trend $(p=0.07)$ in weight loss was observed among females compared with males [45].

Motivation and Sociodemographic Determinants

The study by Kotzampassi et al (2014) focused on delineating a profile of successful responders $(n=162$; $\% \mathrm{EWL} \geq 50 \%$ ) to the IGB treatment compared to poor responders (PR; $n=105$; EWL $\leq 20 \%$ ) considering demographic information and the psychosocial impact of obesity on their lives. Older age, female gender, basic educational level, and single/divorced marital status $(p<0.001)$ were significant determinants of BW loss at IGB removal. Moreover, motivation to lose weight and adherence to treatment (e.g., attendance at a minimum of 4 out of 6 monthly scheduled interviews and commitment to the exercise program) contributed significantly to favorable IGB outcomes $(p=0.001)$. Specifically, the successful re- 
sponder group was motivated by the need to reduce comorbidities, followed by the desire to improve body image and to get pregnant [50].

\section{Psychological Outcomes of IGB Treatment}

Anxiety and Depression

Guedes et al. [46] observed a significant decrease in the level of anxiety (measured by the HADS-A; $p=0.007$ ) and depression (by means of both the BDI, $p=0.002$, and HADS-D, $p=0.03$ scales) among 50 individuals with obesity from baseline to 6 months following the IGB positioning. Reduced anxiety symptoms $(p=0.017)$ were observed in those individuals who showed a greater BW loss at the end of the treatment.

Similarly, in the Deliopoulou et al. (2013) study, a significant reduction of depressive symptoms $(p<0.001)$ from baseline to 3 and 6 months after IGB positioning was detected by means of the BDI-II in a sample of 65 individuals with mild $(n=26)$, moderate $(n=21)$, and severe depression $(n=18)$, with no differences in biomedical parameters at IGB removal. At treatment termination, depressive symptoms were no longer present in 46 out of 65 patients (7.8\%), $13(20 \%)$ out of 26 patients reported mild depression, 5 out of 21 subjects $(7.7 \%)$ had moderate levels of depression, and 1 patient (1.5\%) showed severe depression [48].

\section{Health-Related Quality of Life}

Mui et al. [47] reported a significant pre-post improvement $(p<0.001)$ in 7 out of the 8 domains of the Short Form Health Survey-36 items (SF-36) upon IGB removal in a sample of 119 subjects with obesity, but not in the SF-36 mental health $(p=0.592)$. The impact of the IGB on the HRQoL of patients with obesity was explored by means of the SF-36 also by Guedes et al. [54] and Reimao et al. [53], and both investigations revealed a significant increase in all the SF-36 domains at IGB removal $(p<0.001-0.041)$. Moreover, Tayyem et al. (2011) compared the impact of the IGB $(n=17)$ with laparoscopic adjustable gastric banding (LAGB) $(n=$ 30) on HRQoL and registered a significant improvement in both groups across all the domains of the SF-36 from baseline to a mean follow-up of $14 \pm 6$ months (9 \pm 4 months for the IGB group and $16 \pm 4$ months for LAGB condition; $p<0.001$ ). Still, the LAGB group reported greater HRQoL improvements than the IGB group ( $p=0.025, p=0.011, p=0.024$, respectively) [56]. Both the physical health composite score and mental health composite score composite scores of the SF-12 calculated on a sample of 83 participants by Genco et al.
[58] also showed a statistically significant improvement from baseline to 76 months after positioning of 2 consecutive IGBs $(p<0.001)$. In contrast, Rutten et al. [52] observed a significant HRQoL improvement over 3 measurements in time (baseline, 3 months, and 9 months after IGB placing) only for the physical health composite score composite score of the SF-36 in 19 out of 40 patients with obesity ( $p=0.017)$, while changes in mental health composite score dimension were nonsignificant $(p=0.520)$, with the exception of the SF-36-vitality dimension $(p=0.018)$. Nevertheless, the HealthRelated Quality of Life (HRQL) questionnaire showed a significantly positive change in terms of general wellbeing $(p=0.037)$, health distress $(p=0.005)$, and depression ( $p=0.014$ ) domains in 27 out of 40 individuals at 9 months follow-up, while no significant changes in self-esteem, self-regard, and physical appearance domains were observed [52]. Furthermore, by means of the World Health Organization Quality of Life Instruments (WHOQoL), Guedes et al. [44] registered a significant pre-post IGB improvement in the HRQoL of 50 patients with obesity $(p<0.01-0.05)$.

\section{Quality of Life}

Hiwa (2013) tested the impact of the IGB on the perceived life quality of women treated with the IGB $(n=40)$ compared to those following the Atkins diet $(n=40)$ by means of the Quality of Life Scale (QoLS). Both conditions improved, but statistically significant changes at IGB removal were detected only for the IGB group in 6 out of the 11 dimensions of the questionnaire (feeling happy $[p=0.005]$; satisfaction with the new body image $[p=0.003]$; have better or more regular sex $[p=0.011]$; have better or more regular exercise [ $p=0.011]$; spending more time with friends $[p=0.021]$; and satiety decrease $[p=0.014])$. Instead, the QoLS domains of selfesteem, feeling sexually attractive, nervousness, worrying about unimportant matters, expecting others to tease or use sarcasm, and negative thoughts did not reach significance [57]. De Castro et al. (2010) compared the effect of the air-filled IGB with the saline-filled IGB on the perceived QoL of 33 individuals with obesity by means of the Gastrointestinal Quality of Life Index (GIQLI). With the exception of the GIQLI-physical dimension $(p$ $=0.03$ ), no statically significant between-group differences in scores were observed at 6 months after balloon insertion, and while the HRQoL increased over time in the air-IGB group (92.2 $\pm 18-102.4 \pm 23)$, GIQLI scores decreased in the saline-IGB condition (86.9 $\pm 17-83.6 \pm$ 12). 
Eating Disorders

Genco et al. (2013) made use of the Structured Obesity Diagnostic Interview to evaluate the influence of a single IGB treatment followed by diet (IGB + diet gr.: $n=$ 50 ) with 2 consecutive IGB treatments (IGB + IGB gr.: $n=50$ ) on patients diagnosed with eating disorder not otherwise specified (EDNOS) over 3 measurements in time (baseline, 6 and 13 months after IGB positioning). At the end of follow-up, grazing score $(p<0.001)$, emotional eating, sweet-eating, and after-dinner grazing $(p<$ $0.05)$ decreased significantly in the IGB + IGB group compared with the IGB + diet conditions [49], but no between-group differences were observed after 6 months from the start of treatment.

Satisfaction with Treatment

Tottè et al. (2001) evaluated the impact of obesity on the quality of the social, professional, and relational life perceived by 45 subjects prior to undergoing IGB therapy, and then their satisfaction with treatment was assessed after 3 or 6 months (at the patient's discretion) following the IGB positioning. Results showed the BMI level to affect the individuals' social life (32.5\%) more severely than their relational (14.3\%) and professional (8.7\%) life. Degree of satisfaction correlated poorly with BW loss - and the individuals resulted very satisfied (15\%), satisfied (13\%), reasonably satisfied (22\%), poorly satisfied (8.8\%), or totally unsatisfied (40\%) with the achieved weight reduction at follow-up [51].

\section{Discussion/Conclusion}

This contribution is the first providing a comprehensive summary of the available research literature on the predictive role of anxiety, depression, eating disturbance, and HRQOL/QoL on IGB treatment outcomes, while systematically reviewing the impact of IGB therapy on the individuals' psychological functioning.

Findings from this study revealed that anxiety and depressive levels did not significantly affect the loss of weight of patients with obesity at IGB removal [45], but patients less severely depressed at baseline had a greater weight decrease after 6 months from the IGB positioning [48]. Also, a pre-post higher reduction in the anxiety level was related to a better weight loss [46].

One explanation for these results is that individuals with obesity who ask for surgery or IGB therapy have almost certainly failed a number of previous attempts to lose weight - with consequent weight gain, decrease in their self-efficacy, and increased tendency to give up on losing weight and to rely on external help to succeed. Moreover, a continuous struggle to achieve a healthy weight becomes a source of chronic stress in individuals with obesity [66-68], and ongoing stress, in turn, has been hypothesized to have a pathophysiological role in increasing appetite and stress-related mental disorders such as anxiety and depression [69]. However, unlike surgeries, the IGB treatment might induce less anxiety or fear due to its reversible nature. Also, since higher BMI is commonly associated with greater depression [70, 71], and IGB candidates generally present with lower BMI levels than their surgical counterparts, they might also experience less depressive symptoms that those undergoing bariatric surgeries.

However, these findings may be a result of unspecific assessments of mood disorders, and methodological limitations such as the absence of structured clinical interviews, the use of different self-report measures, or short follow-up periods. Indeed, anxiety and depressive disorders might have a much stronger impact on the course of weight after the IGB treatment than in the early stages and over the duration of treatment, as they might affect the individuals' self-management abilities that are required for effective weight loss maintenance.

Findings from this study also revealed that preexisting binge eating symptoms did not predict BW loss at device removal. However, results varied across selected studies: BMI decreased less among patients with BED compared to their non-binge eating counterparts in 1 study [59], while a trend toward higher BED symptoms was found in those individuals who obtained a loss of weight $>10 \%$ at treatment termination [45]. This contradictory finding might be attributable to several factors including the use of self-report questionnaires instead of objective measures of assessment of binge episodes. Since BED is considered a contraindication for IGB treatment, candidates may have underreported their concerns due to fears of ineligibility for intervention [72].

Moreover, studies have found significantly higher rates of depression in obese persons with BED behavior than those who do not engage in binge episodes [73, 74]. The partial impact of baseline symptoms of BED on treatment outcomes might, therefore, reflect on the study participants' level of depression, and inconsistent results might be further due to the fact that BED can represent a mediator in the relationship between mood disorders and weight loss outcomes in patients undergoing IGB treatment.
12

Obes Facts 2022;15:1-18 DOI: $10.1159 / 000518200$
Pietrabissa et al. 
Older age, female gender, basic education, and single/ divorced marital status were, instead, found to be powerful determinants of BW loss at IGB removal, together with a higher level of motivation to change and adherence to treatment $[45,50]$. Notably, to alleviate comorbidities, to improve body image, and to become pregnant were main reasons for BW loss in those subjects who obtained better outcomes after the IGB intervention. These results support the significance of the patients' intimate values and objectives in determining successful behavioral change $[13,75]$.

In fact, the higher percentage of weight loss achieved by single and divorced patients can be explained by the fact that participants might be motivated to lose weight by the need to improve their physical appearance and increase social opportunities. Accordingly, these patients' social relationships dimension of life quality [45] was the most severely affected by the obesity status. Relationships with others would represent, therefore, an important value driving patients' life and behaviors, which clinicians might focus on as a means of trying to enhance adherence to weight loss treatment, instead of working to increase patients' awareness on the adverse effects that an unhealthy lifestyle might have on their physical and emotional health. Better results were, in fact, achieved by older patients who are commonly aware of all the pros and cons of their behavior, and that - given their chronic condition - usually possess a higher baseline level of BMI than that of younger subjects undergoing IGB therapy. The greater loss in weight registered at the end of the treatment by older patents with obesity may therefore be due to higher baseline biomedical parameters than their younger counterparts, rather than to enhanced compliance to treatment recommendations. Therefore, together with the delivery of nutritional information and the provision of knowledge on the device, preparatory actions to treatment should also focus on strengthening individuals' motivation for change and self-efficacy, so to increase the efficacy and effectiveness of the intervention.

When looking at the IGB outcomes, the findings of this systematic review showed the IGB treatment to have a positive impact on all selected psychological variables (anxiety, depression, HRQoL, QoL, and eating disorder), although the potential role of psychological factors in predicting successful weight loss maintenance remains unclear. Anxiety and depression levels decreased after 6 months from the IGB positioning, and particularly positive effects were observed on depressive symptoms. In fact, the positive feelings associated with weight loss might have improved their mood. However, as a greater

Psychological Correlates of Intragastric Balloon Treatment weight loss commonly occurs early during treatment, the impact of depression might only be temporarily negated to reemerge once the treatment benefits wane [76].

Indeed, most studies reported the maximum timepoint of BW loss after 6 months from the IGB positioning $(n=10)[44,47,49,50,53-55,57-59]$, in 3 records the greatest loss of weight was achieved within 3 months from the start of the treatment $[48,51,52]$, and a single record reported the most consistent BW loss after 2 months [46] and 1 month [45] from baseline measures, respectively. Only 1 study reported the maximum time-point of BW loss after 14 months from the IGB positioning, but no other measurements were made except for the baseline parameters [56].

Accordingly, the findings from this review suggest that perceived HRQoL and QoL improved for most individuals at 3, 9, 14, and 76 months after IGB positioning, with greater benefits at device removal $[44,47,52-58]$ and after positioning of 2 consecutive IGBs [58]. These data further confirm the difficulty for people suffering from overweight and obesity to maintain a healthy lifestyle, and their tendency to rely on external help to succeed in weight loss.

In fact, following the IGB treatment, patients with obesity experienced a greater weight loss and QoL improvements than those who received the Atkins diet [57], while no differences were observed in the perceived QoL of patients receiving different IGB types [55], and bariatric surgery (e.g., LAGB) allowed for better weight loss and HRQoL outcomes than IGB therapy [56]. Moreover, studies that made use of the Short Form Health Survey $[47,53,54,56,58]$ showed a greater benefit in the physical health dimension of the tool, while the SF-36 mental health scores did not always show statistical posttreatment improvement $[47,52]$.

This indicates that patients' adherence to treatment recommendations and perceived life quality following the IGB intervention might not reflect objective outcomes, but their degree of satisfaction with the treatment largely depends on psychological, motivational, and environmental aspects. Indeed, patients' degree of satisfaction correlated weakly with successful BW loss in a single study [51], which showed that almost $50 \%$ of patients reported either a poor level of satisfaction or totally dissatisfaction with the achieved drop in weight resulting from the IGB intervention. Unmet or unrealistic expectations of weight loss, or unchanged negative self-perception following treatment may be related to reemerging general negative affect (e.g., depression and low selfesteem) associated with body dissatisfaction, eating 
patterns and directly with weight status. This again highlights the important role of body image and self-efficacy (e.g., confidence in one's own ability to carry out a particular task), together with the individuals' coping styles and perceived social support, along the pathway [51, 77, 78]. Accordingly, the results from this review show that the QoLS domains of self-esteem, self-regard, negative thoughts, and physical appearance did not reach a statistically significant change following the IGB treatment [52], thus further stressing the need for a proper baseline assessment of these independent variables and the provision of tailored psychological interventions focus on enhancing self-management abilities, and self-efficacy [51, $77,78]$. High BMI is associated with lower body image and self-esteem in many investigations, and the way individuals with obesity feel about their bodies is heavily implicated in the development of psychopathological conditions and the likelihood of continuing weight loss $[25,79,80]$.

The findings of this review also suggest that preintervention dysfunctional eating patterns or clinical diagnosis reduce more consistently for individuals after 2 consecutive IGB treatments than a single IGB treatment followed by diet at up to 13-month follow-up. This is unsurprisingly given that the IGB anatomically restricts the capacity to objectively overeat. Nevertheless, many researchers argue that grazing - defined as the repetitive and unplanned consumption of smaller quantities of food across time - might develop or exacerbate postsurgery dysfunctional eating patterns [81]. Prolonged IGB treatment allowed for a greater reduction in grazing frequency, emotional eating, and sweet-eating than IGB therapy followed by diet [49].

Moreover, the STROBE checklist identified several areas of omission in the selected studies that should be considered while interpreting their findings and provide room for further improvement in research investigating the effects of endoscopic or surgical interventions for weight loss. Only a few contributions reported the setting where the study was conducted or used a flow diagram which helps the readers to understand if the results would generalize to their population and provide information about participants, respectively. Moreover, a single record described analytical methods taking account of sampling strategy [52]. Missing data were also infrequently addressed across the selected contributions, despite representing a potential source of information and determination of attritional bias. Further, only 1 study reported the source of funding [55].
Excellence in reporting is a key component of research that improves the readability and reproducibility of investigations. Therefore, authors are encouraged to consult the STROBE guidelines during manuscript preparation to improve the quality of their reporting, as potential limitations can be considered and addressed prior to data collection.

\section{Limitations of the Current Research}

Due to the methodological limitations of the reviewed articles, the findings of this study should be interpreted carefully. First, the majority of patients undergoing IGB therapy were women, who commonly ask more frequently for weight loss treatment, experience greater levels of psychopathology (e.g., depression and body image disturbances), and suffer more from sociocultural idealization of thinness than men [82]. Also, the lack of follow-up measures did not allow for long-term assessment of weight and psychological status of the participants, together with further considerations on potential dropout rates. Similarly, very few bariatric surgery studies report long-term outcomes with sufficient patient follow-up to minimize biased results and increase postoperative weight loss [83-85].

For most patients, the benefits greatly outweigh the risks, and they are likely to have better and longer lives after bariatric surgery and endoscopic treatment. Still, for the best long-term results, follow-up is key, as neither bariatric surgery nor endoscopic procedures take away the requirement to implement and continue lifestyle modifications and to ensure ongoing management of obesity [86]. Moreover, most of the studies rely on weightrelated scores as the main postoperative outcome, although the improvement of multiple conditions should be considered, including quality-of-life parameters that might further trigger dysfunctional eating patterns if not tackled proactively [87].

In addition, only 1 study [49] made use of structured diagnostic interviews to assess psychological symptoms, thus questioning the reliability and comparability of different self-report instruments. Clinical interviews would, in fact, provide a more in-depth understanding of the individual's baseline psychological features, as well as of their experience with treatment including perceived support, expectations, and challenges.

The limitations of this review to draw reliable conclusions on the psychological correlates of IGB therapy also derive from the small number of studies examining 
each psychological variable in relation with the IGB treatment option. More records could have been found in the literature by enlarging the initial search of databases to younger recipients, by including qualitative studies, or by reviewing endoscopic procedures other than the IGB (e.g., gastric injections, endoscopic sleeve gastroplasty, or aspiration therapy). However, screening of references from a recent systematic review of studies on psychological outcomes following both surgical and endoscopic bariatric procedures [36] did not lead to the inclusion of additional records, and traditional weight loss therapies are usually unfavored as surgical and endoscopic interventions for weight loss in youth. Moreover, the present study did not consider medical complications related to the IGB placement and the preexistence of comorbid diseases among the participants, which may have biased the conclusions over the impact of the therapy on the emotional wellbeing of the IGB recipients.

\section{Implications and Recommendations for Future Research and Clinical Practice}

Although the effect of IGB might be temporary and inferior to those of bariatric surgery, its impact on patient's health is apparent and exceeds those of conventional treatments. Findings from this study highlight the importance of understanding more clearly the baseline psychosocial features that may predict weight loss and the impact that weight fluctuations have on people that experience IGB treatment. Specifically, since self-efficacy is a recognized critical component for successful weight management and a powerful predictor of relapses or worsening of long-term outcomes, further studies should carefully evaluate patients' baseline psychological features and perceived confidence in their ability to achieve behavioral change in order to improve the efficacy and effectiveness of the intervention. Moreover, what patients with obesity hope for and expect from the treatment might further influence their health outcomes. Since unsatisfactory results often bring about negative emotions, impaired task performance, and abandonment of the attempt to achieve the desired weight [88], patients' expectations of treatment should be carefully explored prior to the intervention in order to avoid compensatory responses and relapses.

Therefore, because obesity is a multifactorially caused disease, and given the complex health problems and psychological issues affecting patients with obesity, current findings emphasize the importance of providing multidisciplinary comprehensive preintervention assessment of IGB candidates. This would improve patient selection, optimize patient care, and facilitate the development of cost-effective psychological treatments with the capacity to promote adherence to treatment recommendations and enduring weight loss. Moreover, longer follow-up periods would enable researchers and clinicians to examine the sustained effects of the IGB intervention, and more accurately comment on the long-term psychological outcomes of this endoscopic treatment for weight loss - alone or in comparison with bariatric procedures. Specifically - in line with the bariatric surgery literature - to fully characterize the long-term effect of endoscopic procedures for weight loss, studies should report outcomes for at least $80 \%$ of initial cohorts and with follow-up exceeding 2 years held by a multidisciplinary team [84]. Additionally, future research should examine the role of more pervasive and enduring psychological factors (e.g., personality disorders) in influencing IGB outcomes, so to identifying subgroups of patients who are more likely to experience weight loss difficulties in the short and long term.

\section{Acknowledgment}

The author(s) received no support for the research, authorship, and/or publication of this article.

\section{Statement of Ethics}

All procedures performed in the study were run following the ethical standards of the institutional and/or national research committee and in agreement with the Helsinki Declaration (World Medical Association, 2001) and its later amendments. Ethics statement was not required since the research is a systemic review and meta-analysis of previously published studies.

\section{Conflict of Interest Statement}

The authors declare that the research was conducted in the absence of any commercial or financial relationships that could be construed as a potential conflict of interest.

\section{Funding Sources}

The author(s) received no financial support for the research, authorship, and/or publication of this article. 


\section{Author Contributions}

G.P. contributed to study concept and design; V.B. and A.G.U. contributed to data acquisition; G.P., V.B., and A.G.U. performed data analysis and interpretation; G.P., V.B., A.G.U., S.S., and R.C. drafted the manuscript; and S.B., E.M., G.R., G.C., and E.M. critically revised the manuscript

\section{Data Availability Statement}

All data generated or analyzed during this study are included in this article and its supplementary material files. Further enquiries can be directed to the corresponding author.

\section{References}

1 World Health Organisation. Obesity and overweight: fact sheet 2017. 2017. Available from: http://www.who.int/mediacentre/factsheets/fs311/en/2017

2 Pietrabissa G, Manzoni GM, Corti S, Vegliante N, Molinari E, Castelnuovo G. Addressing motivation in globesity treatment: a new challenge for clinical psychology. Front Psychol. 2012;3:317.

3 Dumon K, Savulionyte G. Bariatric surgery produces greater weight loss and improvements in medical conditions than non-surgical treatment of obesity. Evid Based Med. 2014;19(4):138

4 Pantalone KM, Hobbs TM, Chagin KM, Kong SX, Wells BJ, Kattan MW, et al. Prevalence and recognition of obesity and its associated comorbidities: cross-sectional analysis of electronic health record data from a large US integrated health system. BMJ Open. 2017; 7(11):e017583.

5 Parretti HM, Hughes CA, Jones LL. The rollercoaster of follow-up care' after bariatric surgery: a rapid review and qualitative synthesis. Obes Rev. 2019;20(1):88-107.

6 Genco A, Cipriano M, Bacci V, Cuzzolaro M, Materia A, Raparelli L, et al. BioEnterics Intragastric Balloon (BIB): a short-term, double-blind, randomised, controlled, crossover study on weight reduction in morbidly obese patients. Int J Obes. 2006;30(1):129-33.

7 Nieben OG, Harboe H. Intragastric balloon as an artificial bezoar for treatment of obesity. Lancet. 1982;1:198-9.

8 Kotzampassi K, Grosomanidis V, Papakostas P, Penna S, Eleftheriadis E. 500 intragastric balloons: what happens 5 years thereafter? Obes Surg. 2012;22(6):896-903.

9 Genco A, López-Nava G, Wahlen C, Maselli R, Cipriano M, Sanchez MM, et al. Multi-centre European experience with intragastric balloon in overweight populations: 13 years of experience. Obes Surg. 2013;23(4):515-21.

10 Genco A, Bruni T, Doldi SB, Forestieri P, Marino $\mathrm{M}$, Busetto $\mathrm{L}$, et al. BioEnterics Intragastric Balloon: the Italian experience with 2,515 patients. Obes Surg. 2005;15(8):1161-4.

11 Kotzampassi K, Grosomanidis V, Papakostas P, Penna S, Eleftheriadis E. 500 intragastric balloons: what happens 5 years thereafter? Obes Surg. 2012;22(6):896-903.

12 Pietrabissa G. Group motivation-focused interventions for patients with obesity and binge eating disorder. Front Psychol. 2018;9: 1104.
13 Ceccarini M, Borrello M, Pietrabissa G, Manzoni GM, Castelnuovo G. Assessing motivation and readiness to change for weight management and control: an in-depth evaluation of three sets of instruments. Front Psychol. 2015;6:511.

14 Lindekilde N, Gladstone BP, Lübeck $M$, Nielsen J, Clausen L, Vach W, et al. The impact of bariatric surgery on quality of life: a systematic review and meta-analysis. Obes Rev. 2015;16(8):639-51

15 Sorgente A, Pietrabissa G, Manzoni GM, Re F, Simpson S, Perona S, et al. Web-based interventions for weight loss or weight loss maintenance in overweight and obese people: a systematic review of systematic reviews. J Med Internet Res. 2017;19(6):e229.

16 Yen YC, Huang CK, Tai CM. Psychiatric aspects of bariatric surgery. Curr Opin Psychiatry. 2014;27(5):374-9.

17 Preiss K, Brennan L, Clarke D. A systematic review of variables associated with the relationship between obesity and depression. Obes Rev. 2013;14(11):906-18.

18 Ribeiro GANA, Giapietro HB, Belarmino LB, Salgado-Junior W. Depression, anxiety, and binge eating before and after bariatric surgery: problems that remain. Arq Bras Cir Dig. 2018;31(1):e1356.

19 Caltabiano ML. Translational aspects of body image research for obesity-related quality of life and weight loss maintenance post-bariatric surgery. Ann Transl Med. 2020;8(Suppl 1): S2.

20 Bianciardi E, Di Lorenzo G, Niolu C, Betrò S, Zerbin F, Gentileschi P, et al. Body image dissatisfaction in individuals with obesity seeking bariatric surgery: exploring the burden of new mediating factors. Riv Psichiatr. 2019; 54(1):8-17.

21 Jasik CB. Body image and health: eating disorders and obesity. Prim Care. 2014;41(3): 519-37.

22 Burmeister JM, Hinman N, Koball A, Hoffmann DA, Carels RA. Food addiction in adults seeking weight loss treatment. Implications for psychosocial health and weight loss. Appetite. 2013;60(1):103-10.

23 Degirmenci $\mathrm{T}$, Kalkan Oguzhanoglu N, Sozeri Varma G, Ozdel O, Fenkci S. Psychological symptoms in obesity and related factors. Arch Neuropsychiatr. 2015;52(1):42-6.
24 Pietrabissa G, Castelnuovo G, Manzoni GM, Cattivelli R, Molinari E, Gondoni LA. Psychological well-being as an independent predictor of exercise capacity in cardiac rehabilitation patients with obesity. Front Psychol. 2020;10:2973.

25 McCabe M, Tatangelo G, Watson B, FullerTyszkiewicz M, Rodgers RF, Aimé A, et al. Development and testing of a model for risk and protective factors for eating disorders and higher weight among emerging adults: a study protocol. Body image. 2019;31:139-49.

26 Lin HY, Huang CK, Tai CM, Lin HY, Kao YH, Tsai CC, et al. Psychiatric disorders of patients seeking obesity treatment. BMC Psychiatry. 2013;13(1):1.

27 Rutledge T, Groesz LM, Savu M. Psychiatric factors and weight loss patterns following gastric bypass surgery in a veteran population. Obes Surg. 2011;21(1):29-35.

28 Merrell J, Ashton K, Windover A, Heinberg L. Psychological risk may influence drop-out prior to bariatric surgery. Surg Obes Relat Dis. 2012;8(4):463-9.

29 Moura D, Oliveira J, De Moura EG, Bernardo W, Galvao Neto M, Campos J, et al. Effectiveness of intragastric balloon for obesity: a systematic review and meta-analysis based on randomized control trials. Surgery for obesity and related diseases. Surg Obes Relat Dis. 2016;12(2):420-9.

30 Imaz I, Martínez-Cervell C, García-Alvarez EE, Sendra-Gutiérrez JM, González-Enríquez J. Safety and effectiveness of the intragastric balloon for obesity. A meta-analysis. Obes Surg. 2008;18(7):841-6.

31 Mui WL, Ng EK, Tsung BY, Wang RZ, Cheng AY, Yau PY, et al. [Effectiveness and safety of intragastric balloon for treatment of morbid obesity]. Zhonghua yi xue za zhi. 2007;87(6): 388-91 .

32 Szmulewicz A, Wanis KN, Gripper A, Angriman F, Hawel J, Elnahas A, et al. Mental health quality of life after bariatric surgery: a systematic review and meta-analysis of randomized clinical trials. Clin Obes. 2019;9(1): e12290.

33 O’Brien PE, Hindle A, Brennan L, Skinner S, Burton P, Smith A, et al. Long-term outcomes after bariatric surgery: a systematic review and meta-analysis of weight loss at 10 or more years for all bariatric procedures and a singlecentre review of 20-year outcomes after adjustable gastric banding. Obes Surg. 2019; 29(1):3-14. 
34 Magallares A, Schomerus G. Mental and physical health-related quality of life in obese patients before and after bariatric surgery: a meta-analysis. Psychol Health Med. 2015; 20(2):165-76.

35 Wimmelmann CL, Dela F, Mortensen EL. Psychological predictors of mental health and health-related quality of life after bariatric surgery: a review of the recent research. Obes Res Clin Pract. 2014;8(4):e314-24.

36 Spirou D, Raman J, Smith E. Psychological outcomes following surgical and endoscopic bariatric procedures: a systematic review. Obes Rev. 2020;21(6):e12998.

37 Page MJ, McKenzie JE, Bossuyt PM, Boutron I, Hoffmann TC, Mulrow CD, et al. The PRISMA 2020 statement: an updated guideline for reporting systematic reviews. BMJ. 2021;372: n71.

38 Huang X, Lin J, Demner-Fushman D. Evaluation of PICO as a knowledge representation for clinical questions. AMIA Annu Symp Proc. 2006;2006:359-63.

39 Coulman KD, Abdelrahman T, Owen-Smith A, Andrews RC, Welbourn R, Blazeby JM. Patient-reported outcomes in bariatric surgery: a systematic review of standards of reporting. Obes Rev. 2013;14(9):707-20.

40 Johnson K. Database search tips and tricks. Los Angeles, CA: Meriam Library, California State University; 2002. Available from: https: //www.csuchico.edu/lins/handouts/Database_Search_Tips.pdf Accessed 2017 Jun 1. [WebCite Cache ID6qu6CTOLx].

41 Tate CM, Geliebter A. Intragastric balloon treatment for obesity: review of recent studies. Adv Ther. 2017;34(8):1859-75.

42 Dumonceau JM. Evidence-based review of the bioenterics intragastric balloon for weight loss. Obes Surg. 2008;18(12):1611-7.

43 Smith V, Devane D, Begley CM, Clarke M. Methodology in conducting a systematic review of systematic reviews of healthcare interventions. BMC Med Res Methodol. 2011; 11(1): 15 .

44 Guedes EP, Madeira E, Mafort TT, Madeira M, Moreira RO, de Mendonça LMC, et al. Impact of 6 months of treatment with intragastric balloon on body fat and quality of life in obese individuals with metabolic syndrome. Health Qual Life Outcomes. 2017;15(1):211.

45 Madeira E, Madeira M, Guedes EP, Mafort TT, Neto LV, de Oliveira Moreira R, et al. Assessment of predictive response factors to intragastric balloon therapy for the treatment of obesity. J Laparoendosc Adv Surg Tech A. 2016;26(3):168-73.

46 Guedes EP, Madeira E, Mafort TT, Madeira M, Moreira RO, Mendonça LM, et al. Impact of a 6-month treatment with intragastric balloon on body composition and psychopathological profile in obese individuals with metabolic syndrome. Diabetol Metab Syndr. 2016; 8:81.
47 Mui WL, Ng EK, Tsung BY, Lam CH, Yung MY. Impact on obesity-related illnesses and quality of life following intragastric balloon. Obes Surg. 2010;20(8):1128-32.

48 Deliopoulou K, Konsta A, Penna S, Papakostas $\mathrm{P}$, Kotzampassi K. The impact of weight loss on depression status in obese individuals subjected to intragastric balloon treatment. Obes Surg. 2013;23(5):669-75.

49 Genco A, Maselli R, Frangella F, Cipriano M Paone E, Meuti V, et al. Effect of consecutive intragastric balloon $\left(\mathrm{BIB}^{\circ}\right)$ plus diet versus single $\mathrm{BIB}^{\circledast}$ plus diet on eating disorders not otherwise specified (EDNOS) in obese patients. Obes Surg. 2013;23(12):2075-9.

50 Kotzampassi K, Shrewsbury AD, Papakostas P, Penna S, Tsaousi GG, Grosomanidis V. Looking into the profile of those who succeed in losing weight with an intragastric balloon. J Laparoendosc Adv Surg Tech A. 2014;24(5): 295.

51 Totte E, Hendrickx L, Pauwels M, Van Hee R. Weight reduction by means of intragastric device: experience with the bioenterics intragastric balloon. Obes Surg. 2001;11(4):519-23.

52 Rutten SJ, de Goederen-van der Meij S, Pierik RG, Mathus-Vliegen EM. Changes in quality of life after balloon treatment followed by gastric banding in severely obese patients: the use of two different quality of life questionnaires. Obes Surg. 2009;19(8):1124-31.

53 Reimao SM, da Silva MER, Nunes GC, Mestieri LHM, Dos Santos RF, de Moura EGH. Improvement of body composition and quality of life following intragastric balloon. Obes Surg. 2018;28(6):1806-8.

54 Guedes MR, Fittipaldi-Fernandez RJ, Diestel CF, Klein M. Changes in body adiposity, dietary intake, physical activity and quality of life of obese individuals submitted to intragastric balloon therapy for 6 months. Obes Surg. 2019;29(3):843-50.

55 De Castro ML, Morales MJ, Del Campo V, Pineda JR, Pena E, Sierra JM, et al. Efficacy, safety, and tolerance of two types of intragastric balloons placed in obese subjects: a double-blind comparative study. Obes Surg. 2010;20(12):1642-6.

56 Tayyem RM, Obondo C, Ali A. Short-term outcome and quality of life of endoscopically placed gastric balloon and laparoscopic adjustable gastric band. Saudi J Gastroenterol. 2011;17(6):400-5.

57 Hiwa OA. Quality of life of the obese patients after treatment with insertion of intragastric BIB balloon versus Atkins diet in Al Sulaimaneyah province-Iraq. Food Sci Qual Manage. 2013;20:29-36.

58 Genco A, Maselli R, MC, Michele L, Basso N, Redler A. Long-term multiple intragastric balloon treatment: a new strategy to treat morbid obese patients refusing surgery: prospective 6-year follow-up study. Surg Obes Relat Dis. 2014;10(2):307-11.
59 Puglisi F, Antonucci N, Capuano P, Zavoianni L, Lobascio P, Martines G, et al. Intragastric balloon and binge eating. Obes Surg. 2007;17: 504-9.

60 Zheng Y, Wang M, He S, Ji G. Short-term effects of intragastric balloon in association with conservative therapy on weight loss: a meta-analysis. J Transl Med. 2015;13:246.

61 Popov VB, Ou A, Schulman AR, Thompson CC. The impact of intragastric balloons on obesity-related co-morbidities: a systematic review and meta-analysis. Am J Gastroenterol. 2017;112(3):429-39.

62 Gadd N, McIntosh A, Fear-Keen B, Hoult J, Maimone IR, Marshall S. Do endoscopic bariatric procedures improve postprocedural quality of life and mental health? A systematic review and meta-analysis. Obes Surg. 2020;30:1-10.

63 Spirou D, Raman J, Smith E. Psychological outcomes following surgical and endoscopic bariatric procedures: a systematic review. Obes Rev. 2020;21(6):e12998.

64 Moher D, Liberati A, Tetzlaff J, Altman DG. Preferred reporting items for systematic reviews and meta-analyses: the PRISMA statement. Int J Surg. 2010;8(5):336-41.

65 von Elm E, Altman DG, Egger M, Pocock SJ, Gøtzsche PC, Vandenbroucke JP. The Strengthening the Reporting of Observational Studies in Epidemiology (STROBE) statement: guidelines for reporting observational studies. Lancet. 2007;370(9596):1453-7.

66 Jackson JB, Pietrabissa G, Rossi A, Manzoni GM, Castelnuovo G. Brief strategic therapy and cognitive behavioral therapy for women with binge eating disorder and comorbid obesity: a randomized clinical trial one-year follow-up. J Consult Clin Psychol. 2018;86(8):688-701.

67 Mann T, Tomiyama AJ, Westling E, Lew AM, Samuels B, Chatman J. Medicare's search for effective obesity treatments: diets are not the answer. Am Psychol. 2007;62(3):220-33.

68 Pietrabissa G, Castelnuovo G, Jackson JB Rossi A, Manzoni GM, Gibson P. Brief strategic therapy for bulimia nervosa and binge eating disorder: a clinical and research protocol. Front Psychol. 2019;10:373.

69 van der Valk ES, Savas M, van Rossum EFC Stress and obesity: are there more susceptible individuals? Curr Obes Rep. 2018;7(2):193203.

70 Moscarelli M, Manning W. Effects of major depression on obesity. J Ment Health Policy Econ. 2011;14(4):163-4.

71 Opel N, Redlich R, Grotegerd D, Dohm K, Heindel W, Kugel H, et al. Obesity and major depression: body-mass index (BMI) is associated with a severe course of disease and specific neurostructural alterations. Psychoneuroendocrinology. 2015;51:219-26.

72 Ambwani S, Boeka AG, Brown JD, Byrne TK, Budak AR, Sarwer DB, et al. Socially desirable responding by bariatric surgery candidates during psychological assessment. Surgery for obesity and related diseases. Off J Am Soc Bariatr Surg. 2013;9(2):300-5.
Psychological Correlates of Intragastric Balloon Treatment
Obes Facts 2022:15:1-18

DOI: $10.1159 / 000518200$ 
73 Specker S, de Zwaan M, Raymond N, Mitchell J. Psychopathology in subgroups of obese women with and without binge eating disorder. Compr Psychiatry. 1994;35:185-90.

74 Yanovski SZ, Nelson JE, Dubbert BK, Spitzer RL. Association of binge eating disorder and psychiatric comorbidity in obese subjects. Am J Psychiatry. 1993;150(12):1472-9.

75 Pietrabissa G, Manzoni GM, Rossi A, Castelnuovo G. The MOTIV-HEART Study: a prospective, randomized, Single-Blind Pilot Study of brief strategic therapy and motivational interviewing among cardiac rehabilitation patients. Front Psychol. 2017;8:83.

76 Buddeberg-Fischer B, Klaghofer R, Krug L, Buddeberg C, Müller MK, Schoeb O, et al. Physical and psychosocial outcome in morbidly obese patients with and without bariatric surgery: a 4 1/2-year follow-up. Obes Surg. 2006;16(3):321-30.

77 Teixeira PJ, Palmeira AL, Branco TL, Martins SS, Minderico CS, Barata JT, et al. Who will lose weight? A reexamination of predictors of weight loss in women. Int J Behav Nutr Phys Act. 2004;1(1):12.
78 van Hout GC, Hagendoren CA, Verschure SK, van Heck GL. Psychosocial predictors of success after vertical banded gastroplasty. Obes Surg. 2009;19(6):701-7.

79 Aime A, Fuller-Tyszkiewicz M, Dion J, Markey CH, Strodl E, McCabe M, et al. Assessing positive body image, body satisfaction, weight bias, and appearance comparison in emerging adults: a cross-validation study across eight countries. Body Image. 2020;35:320-32.

80 Pietrabissa G, Gullo S, Aimé A, Mellor D, McCabe M, Alcaraz-Ibánez M, et al. Measuring perfectionism, impulsivity, self-esteem and social anxiety: cross-national study in emerging adults from eight countries. Body Image. 2020;35:265-78.

81 Chao AM, Wadden TA, Faulconbridge LF, Sarwer DB, Webb VL, Shaw JA, et al. Binge-eating disorder and the outcome of bariatric surgery in a prospective, observational study: two-year results. Obesity. 2016;24(11):2327-33.

82 Friedman MA, Brownell KD. Psychological correlates of obesity: moving to the next research generation. Psychol Bull. 1995;117(1): 3-20.
83 Biron S, Biertho L, Marceau S, Lacasse Y. Long-term follow-up of disease-specific quality of life after bariatric surgery. Surg Obes Relat Dis. 2018;14(5):658-64.

84 Puzziferri N, Roshek TB 3rd, Mayo HG, Gallagher R, Belle SH, Livingston EH. Long-term follow-up after bariatric surgery: a systematic review. JAMA. 2014;312(9):934-42.

85 Thereaux J, Lesuffleur T, Paita M, Czernichow S, Basdevant A, Msika S, et al. Long-term follow-up after bariatric surgery in a national cohort. Br J Surg. 2017;104(10):1362-71.

86 Christensen BJ, Schmidt JB, Nielsen MS, Tækker L, Holm L, Lunn S, et al. Patient profiling for success after weight loss surgery (GO Bypass study): an interdisciplinary study protocol. Contemp Clin Trials Commun. 2018; 10:121-30.

87 Richardson WS, Plaisance AM, Periou L, Buquoi J, Tillery D. Long-term management of patients after weight loss surgery. Ochsner J. 2009;9(3):154-9.

88 Dalle Grave R, Calugi S, Molinari E, Petroni ML, Bondi M, Compare A, et al. Weight loss expectations in obese patients and treatment attrition: an Observational Multicenter Study. Obes Res. 2005;13(11):1961-9. 